\title{
SECM imaging of the cut edge corrosion of galvanized steel as a function of $\mathbf{p H}$
}

\author{
A.G. Marques ${ }^{\mathrm{a}, \mathrm{b}}$, J. Izquierdo ${ }^{\mathrm{c}}$, R. M. Souto ${ }^{\mathrm{c}}$, A.M. Simões ${ }^{\mathrm{a}, \mathrm{b}}$ \\ ${ }^{a}$ ICEMS -Institute of Materials and Surfaces Science and Engineering , Av. Rovisco Pais, 1049-001 Lisboa, \\ Portugal \\ ${ }^{b}$ Department of Chemical Engineering, Instituto Superior Técnico, University of Lisbon, Av. Rovisco Pais, \\ 1049-001 Lisboa, Portugal \\ ${ }^{c}$ Department of Chemistry, University of La Laguna, P.O. Box 456, E-38200 La Laguna, Tenerife, Canary \\ Islands, Spain \\ *Corresponding author: alda.simoes@tecnico.ulisboa.pt
}

\begin{abstract}
Scanning electrochemical microscopy (SECM) and the Scanning vibrating electrode technique (SVET) were employed to identify the local reactivity and the cathodes and anodes on a cut edge of galvanized steel. The SECM was used in the amperometric feedback mode (for the oxidation of ferrocenemethanol as mediator) for sensing the conductivity of the surface and in the redox competition mode for locating the depletion of the cathodic reactant. Good agreement was observed in acidic solution between the location of the conductive regions of the surface and the depletion of oxygen estimated from amperometric lines across the cut edge. In neutral medium, non-uniform activity of the steel surface was observed and correlated well with the ionic current flows in solution and with the accumulation of zinc corrosion products on steel. In alkaline medium, the entire metallic surface operated as electron source for the regeneration cycle of the redox mediator. Irrespective of the $\mathrm{pH}$ of the solution, a maximum of the feedback observed over the cut edge is consentaneous with the thermodynamic stability of iron in the reduced form. SECM provided useful information regarding the steel conductivity, whereas the zinc anodes could only be resolved by the SVET.
\end{abstract}

Keywords: cut edge; corrosion; pH; SECM; SVET. 


\section{Introduction}

Galvanized steel is widely used in the automotive and construction industries because the thin zinc layer sacrificially protects steel, thus assuring integrity and functionality of the structure for a longer time. Though many studies have dealt with the corrosion of galvanized steel, only few describe the phenomenon at a microscopic level. Conventional electrochemical techniques such as DCpolarization, cyclic voltammetry and electrochemical impedance spectroscopy (EIS), are widely used to study the metal/electrolyte interface phenomena in corrosion processes [1], but they lack spatial resolution, which can be a drawback when characterizing processes that either are triggered at micrometer or sub-micrometer scales, or are localized in nature. Thus, researchers in the field are increasingly employing local electrochemical methods to investigate these systems. Investigations using the scanning reference electrode technique (SRET) [2-6], the scanning Kelvin probe (SKP) [712], and localized electrochemical impedance spectroscopy (LEIS) [13-17] have provided excellent information on the mechanisms of localized corrosion in various systems. These techniques are mostly based upon the measurement of an electrical response as a consequence of the electrochemical activity of the system, like the ionic currents in the electrolyte, potential distributions either on the substrate or in the electrolyte around the active sites in the substrate, or impedance response to an AC perturbation.

In particular, the scanning vibrating electrode technique (SVET) is a powerful technique that provides information on the location, intensity and direction of ionic currents in solution, thus sensing the microscopic anodes and cathodes on an active surface and is probably the most popular of the surface-resolved electrochemical techniques due to its ease of use and straightforward interpretation [18-20]. The use of a vibrating probe enhances the spatial resolution and is particularly useful for galvanic processes [21] and pitting corrosion [22]. The scanning electrochemical microscope (SECM) corresponds to a set of techniques that has the advantage of probing a variety of electrochemical reactions and provide electrochemical sensitivity to characterize both surface topography and the redox activities at the metal/electrolyte interface [23-27]. Concentration gradients of particular species can under some conditions be assessed, and this makes the technique complementary to the SVET.

Operation of the SECM in the amperometric feedback mode is done by applying a potential step to the ultramicroelectrode (UME) in the presence of a reversible redox couple. When this redox substance, the electrochemical mediator, is added in its reduced state and the UME is biased to the potential of oxidation of the mediator under diffusion conditions, a limiting current, $\mathrm{i}_{\mathrm{L}}$, is defined by Eq.1, for a disk shaped UME [25].

$$
\mathrm{i}_{\mathrm{L}}=4 \mathrm{nFDCa}
$$


In this, D is the diffusion coefficient of the species, C is its bulk concentration, F the Faraday constant, $\mathrm{n}$ the number of electrons involved in the reaction and a is the conductive probe radius.

The SECM has been employed to detect metal dissolution by sensing the released species [2831], to image precursor sites for pitting corrosion [32-35], to monitor metastable nucleation and propagation of corrosion pits [36-38], to visualize the permeability of protective coatings applied on metallic substrates to chemical species in the environment [39-42], and to follow the degradation reactions in defective coatings [43-48].

Given their complementarities, the SVET and the SECM combined can be a powerful tool for small scale systems with well defined electrodes. In the cut edge, the small thickness of the anode in comparison with the steel cathode, as well as the proximity between the electrodes and the high gradients of ion concentration and $\mathrm{pH}$ in particular, make this traditional system a unique galvanic couple of great scientific interest.

In this work we report an investigation on the corrosion reactions occurring on an electrogalvanized steel sample. The zinc layers were located on both sides of the steel substrate, placed in a cut edge configuration; further, a graphite-containing polymer was applied to one of the sides of the metal. The rationale for choosing this configuration was to more easily discern the influences exerted by the different layers on the corrosion resistance of the steel substrate. The study uses both the SECM and the SVET, because they are electrochemical techniques that allow adequate spatial resolution for the target system.

The SECM operated in the feedback and redox competition modes was employed to monitor electrochemical activity and also to explore the influence of $\mathrm{pH}$ on the corrosion reactions. Though SVET and pH sensors have already been used to investigate galvanized steel or Zn-Al coated steel cut edge systems [20,49-58] and good agreement with models based on numerical simulation methods was found [59], very little has been published using the SECM, for galvanic corrosion [60]. In a recent work [61], a cut edge coated with Aluzinc ${ }^{\circledR}$ and a polymeric coating was studied with amperometric and potentiometric SECM tips and it was shown that in neutral $\mathrm{NaCl}$ electrolyte, the polymeric coating originates asymmetrical reactivity on the sample due to a differential aeration mechanism. Further, local acidification was measured next to the active anode and alkalinization on the remaining cut edge surface.

The onset of electrochemical corrosion should be observed through the development of local anodes and cathodes in the defective system, with the formation of soluble zinc species. The latter, depending on the $\mathrm{pH}$ of the electrolyte solution directly in contact with the corroding edge, might either diffuse in the electrolyte or precipitate at the interface with the formation of oxy-hydroxides. Further, in a cut edge the anode and the cathode develop specific chemistries, namely $\mathrm{pH}$ differences resulting 
from each of the electrochemical reactions occurring at the two half-cells. The influence of $\mathrm{pH}$ on the corrosion of zinc has been discussed in detail by Thomas et al. [62], who concluded that at $\mathrm{pH}<3$, active dissolution of zinc occurs under kinetic control of the cathodic reaction (predominantly hydrogen evolution reaction, HER), whereas in less acidic environments (namely for $\mathrm{pH} 4$ to 5) a domain of pseudo-passivity was observed in the form of zinc oxides directly formed from the surface [62]. Pourbaix diagrams predict passivation for zinc above $\mathrm{pH} 7$ [63], yet dissolution of the passive layer due to metal hydrolysis may occur for $\mathrm{pH}$ values up to 10 [62]. Although surface oxides do not effectively passivate the metal in weak alkaline conditions, they may act as a barrier to the $\mathrm{OH}^{-}$ions, thus protecting the metal to a certain extent. Finally, protective zinc oxides are formed when the local $\mathrm{pH}$ is above 11 [62]. On this basis, it was decided to investigate the corrosion reactions at the cut edges of polymer-coated galvanized steel using scanning microelectrochemical techniques at three selected pH values, namely 2, 5 and 10, in non-buffered solutions. These values are representative of the three main distinctive behaviours for zinc corrosion as function of $\mathrm{pH}$.

\section{Experimental}

\subsection{Materials}

The substrate consisted of electrogalvanized steel with a nominal zinc thickness of $7.2 \mu \mathrm{m}$ applied industrially on either side of a steel sheet with a width of $800 \mu \mathrm{m}$. A thin epoxy layer $(1.2 \mu \mathrm{m})$ was applied to the zinc on one of the sides. The sheets were cut and mounted into an epoxy resin sleeve, leaving an exposed cut edge approximately $5 \mathrm{~mm}$ long. As a consequence of the resin contraction during curing, a narrow gap was formed between the epoxy layer and the zinc. This procedure generated an active zinc anode along that interface, thus providing some control of the location of the anode. The scanning direction was always across the cut edge, starting from the side of the epoxy layer, i.e., of the active zinc. The working surface of the mount was polished using silicon carbide paper under ethanol to 1000 grit finish, cleaned thoroughly in an ultrasonic bath after each grinding step, finally rinsed in ethanol, and allowed to dry in air. A small electrochemical cell was built by surrounding the mount laterally with Sellotape and completed with a platinum strip as counter electrode and a $\mathrm{Ag} / \mathrm{AgCl}, 3 \mathrm{M} \mathrm{KCl}$ reference electrode. All the potential values reported herein are referred to this reference electrode. Testing was made in quiescent $10 \mathrm{mM} \mathrm{NaCl}$ aqueous solution, naturally-aerated, at ambient temperature. Adjustment of the $\mathrm{pH}$ was made by adding $\mathrm{HCl}$ or $\mathrm{NaOH}$ to the electrolyte. Millipore deionised water and analytical grade chemicals were employed. The cut edge system was left non-polarized, i.e., under spontaneously-driven corrosion.

\subsection{Potential-time curves}


DC potential-time curves at open circuit measurements were made using an ACM Field Machine (ACM Instruments, U.K.) controlled by a personal computer equipped with ACM software, version 5. Testing was performed in cells similar to those described in the previous section.

\subsection{SECM instrumentation and experimental procedure}

Measurements were made using a Sensolytics scanning electrochemical microscope (Bochum, Germany). The electrochemical interface was an Autolab PGSTAT 128N (Ecochemie, Utrecht, The Netherlands). The system operated in a three-electrode configuration in which the SECM probe was a platinum disk UME of $12.5 \mu \mathrm{m}$ diameter sheathed in a glass rod with a conical shape at the bottom. The diameter of the insulating sheath was about 20 times the size of the platinum disk. The electrochemical cell and the positioning device were placed inside a Faraday cage. Operation of the SECM was made sequentially in two modes, the feedback mode with a redox mediator and the competition mode for the cathodic reactant. The feedback mode was applied for studying the surface concerning distribution of electrochemical reactivity, using ferrocenemethanol (abbreviated as FcMeOH, Sigma-Aldrich) as redox mediator. This is a neutral species that undergoes a fully reversible oxidation at $+0.216 \mathrm{~V}[24]$ to form a stable species, ferrocinium, according to:

$$
\mathrm{FcMeOH} \leftrightarrow \mathrm{FcMeOH}^{+}+\mathrm{e}^{-}
$$

The redox potential for this equilibrium is very positive compared to the open circuit potential of the cut edge samples (around $-0.80 \mathrm{~V}$ ), which means that ferrocenemethanol is the only form of the mediator in bulk solution. In the vicinity of a conductive surface and if the potential of the tip is sufficiently high to cause oxidation of the mediator, the oxidised species will quickly become reduced at the surface, increasing the current at the tip compared to the bulk current.

Leveling of the sample was first made using a bubble level and then confirmed by performing z-approach curves at two distant points above the resin on each side of the cut edge. The operating distance between the tip and the sample was set after recording $z$-approach curves above the resin. Positioning of the tip was made by holding it at a constant potential of $+0.50 \mathrm{~V}$ and approaching the surface of the resin until the current dropped to $30 \%$ of $i_{L}$. Subsequently, the tip was withdrawn by 10 $\mu \mathrm{m}$ away from that point, to a distance to the surface estimated as $\sim 20 \mu \mathrm{m}$; in this way it was still ensured that the probe was kept inside the diffusion layer, while any bumping against corrosion products accumulating on the surface during the experiment was prevented. We assume that polishing produced a sufficiently flat surface and that the chosen working distance was large enough in order to exclude topography effects from the interpretation of results. 
The competition mode was used for mapping the concentration of cathodic reactants in solution in the diffusion layer of the corroding surface [23]. The main cathodic reaction occurring on steel is the reduction of oxygen -Eq.3- or water - Eq.4- when exposed to alkaline or neutral aqueous electrolytes and HER, Eq.5, in acidic medium [62]. If the tip is biased in the potential range at which oxygen reduction or hydrogen evolution proceeds under diffusion control, competition for these species is established between the tip and the substrate.

$$
\begin{gathered}
\mathrm{O}_{2}+2 \mathrm{H}_{2} \mathrm{O}+4 \mathrm{e}^{-} \rightarrow 4 \mathrm{OH}^{-} \\
4 \mathrm{H}_{2} \mathrm{O}+4 \mathrm{e}^{-} \rightarrow 4 \mathrm{OH}^{-}+2 \mathrm{H}_{2} \\
2 \mathrm{H}^{+}+2 \mathrm{e}^{-} \rightarrow \mathrm{H}_{2}
\end{gathered}
$$

A decrease in the reduction current measured potentiostatically at the tip is then associated with depletion of oxygen/protons at the probe and thus with a cathodic site on the substrate [30, 40].

The concentration of ferrocenemethanol in the test electrolytes was $0.5 \mathrm{mM}$ and the scans were made with the tip parallel to the surface, at constant height, at a scan rate of $5.6 \mu \mathrm{m} \mathrm{s}^{-1}$. Voltammograms were also recorded with the aim of help selecting the tip potential for the amperometric study. These curves were at obtained using the SECM instrumentation, the tip as the working electrode, in a cell without the introduction of the cut edge sample, and at $20 \mathrm{mV} \mathrm{s}^{-1}$ scan rate.

\subsection{SVET instrumentation and experimental procedure}

The SVET instrumentation (Applicable Electronics Inc., New Haven, CT, USA) was controlled by ASET software (Science Wares ${ }^{\mathrm{TM}}$, Falmouth, MA, USA). The microelectrode consisted of a platinum wire sheathed with an insulating polymer, except for the tip, which was electro-platinized to obtain a sphere with approximately $20 \mu \mathrm{m}$ of diameter. The scans were performed with the tip positioned $100 \mu \mathrm{m}$ above the surface and vibrating at $300 \mathrm{~Hz}$ in the vertical direction, with $20 \mu \mathrm{m}$ amplitude, allowing the potential gradient in solution to be measured accurately. A calibration routine allowed transforming the potential gradients into current density and single lines across the cut edge, with step increments of $10 \mu \mathrm{m}$ were measured. The time required to record a single line scan was ca. 2 minutes. The graphs depict the vertical component of the current density vector.

\section{Results}

The chemical stability and the potential range for the diffusion-limited oxidation of FcMeOH at the UME were determined by recording the corresponding voltammograms in the electrolytes shortly after immersion, Figure 1(a). The shape and current values in the voltammograms were practically independent of the $\mathrm{pH}$. The experimental values of the half-wave potential for the oxidation of ferrocenemethanol were in the range +0.20 to $+0.27 \mathrm{~V}$, above which a limiting diffusion current for 
the oxidation process $\left(\mathrm{i}_{\mathrm{L}} \approx 0.4 \mathrm{nA}\right)$ was registered. A constant potential of +0.45 to $+0.50 \mathrm{~V}$ was applied to the tip for amperometric analysis of the rate of regeneration of the mediator. This potential is located in the diffusion plateau for the oxidized species and therefore the current measured at the tip will be proportional to the local concentration of FcMeOH. This means that when the tip passes over a conductive region of our target the current should increase, whereas at the insulating areas it should decrease.

A comparable principle was applied to monitor the cathodic reactions at the cut edge sample. Thus, voltammograms recorded in the cathodic region show a plateau in all the solutions, Figure 1(b). The tip potential was set in the region of the plateau for monitoring the concentration of oxygen in solution. The results presented were obtained at a constant tip potential of $-0.50 \mathrm{~V}$.

The spontaneous potential of the cut edge electrodes was measured during immersion in naturally aerated $\mathrm{NaCl}$ solution. At neutral $\mathrm{pH}$ the potential was quite stable and in the range of the corrosion potential for zinc - Figure 2. At pH 10 the potential had some fluctuations but was also in the range of zinc corrosion potential, whereas at $\mathrm{pH} 2$ the high rate of zinc dissolution resulted in loss of sacrificial protection of steel after approximately one hour, i.e., after dissolution of the uppermost part of the zinc layer and possible blocking of the zinc by corrosion products, causing ohmic drop between the zinc at the bottom of the gap and the outer steel; under these conditions the potential shifted up to values at which steel is active.

\section{1. $p H=2$}

At this $\mathrm{pH}$, the attack of the solution to the cut edge was revealed by intense hydrogen bubbling, which gradually became less intense and concentrated at the sides. The approach curves for the oxidation of the mediator revealed negative feedback above the insulating resin and positive feedback over the cut edge, which means that the cut edge is conductive (i.e., the mediator is reduced at the cut edge surface at its spontaneous potential) and the resin is insulating. When the tip is set to a negative potential, the current is smaller in magnitude near the cathodes on the surface. Further, the amperometric curves have shown distinct patterns in the initial state, i.e., when the galvanic protection was active, and in the second stage, when steel was not protected. At short immersion times the cathodic current measured in the competition mode (tip potential $=-0.50 \mathrm{~V}$ ) has a minimum over the entire cut edge, Figure 3 that reveals depletion of the species reduced at the tip. This means that the tip and the cut edge are competing for the reduction of the same species. Meanwhile, the curve obtained at $+0.50 \mathrm{~V}$ depicts a plateau extending across the cut edge. This plateau shows a current drift in the direction of the scan, which results not from tilting of the sample (the curves in the reverse direction 
reveal a continuous current drop), but most likely from a progressive change of the surfaces that decreases the rate of regeneration of the mediator, for example, due to adsorption of species from the solution $[64,65]$ All subsequent scans showed the same trend and identical observations have been reported in previous studies [15].

As time elapsed, and after zinc had ceased protecting steel, a local peak of feedback current was observed near the edge coated with an organic layer, matching a cathodic peak observed at the same location - Figure 4. These peaks were reproducible and their meaning is not totally straightforward. A maximum in the feedback current after some time of exposure might be explained by topography, i.e. by the development of a hill of conductive material on the surface. This hypothesis, however, is unlikely in this system, as the only species that might precipitate are corrosion products, which are normally not conductive; further, there were no signs of precipitation at this $\mathrm{pH}$. Therefore, the current profiles observed at long exposure times are most likely due to corrosion activity of steel near the gap.

Microscopic inspection at the end of the experiment has shown non-adherent corrosion products all over the steel surface, most likely resulting from precipitation after removal of the electrolyte, during the drying stage - Figure 5. Corrosion was quite asymmetric. The edge at the bottom corresponds to the organic coating side where zinc dissolution was more intense and near the locations at which the amperometric peaks were found.

\section{2. $p H=10$}

For a freshly ground cut edge immersed in solution at $\mathrm{pH} 10$ and when the tip potential was set at $+0.45 \mathrm{~V}$ for the oxidation of ferrocenemethanol, the current at the tip exhibited a plateau approximately $880 \mu \mathrm{m}$ wide, i.e., covering the entire width of the sample - Figure 6. The potential of the galvanic couple was roughly in the range -1.00 to $-0.95 \mathrm{~V}$. At this potential the thermodynamically stable forms of zinc are $\mathrm{ZnO}$ or $\mathrm{Zn}(\mathrm{OH})$, while iron is immune, according to the respective Pourbaix diagrams [63]. The cathodic currents at the microelectrode (not shown) were very low and noisy, but the feedback currents for the oxidation of the mediator give a plateau over the cut edge, meaning that ferrocenemethanol becomes regenerated at the steel surface.

The general shape of the plateau remained mostly unchanged for the first couple of hours, revealing no signs of heterogeneity in local activity over the substrate. The decrease of the current in subsequent curves may result from two factors: the precipitation of zinc oxides on the steel surface, making the surface less conductive and therefore less effective in the regeneration of the mediator and possibly some blocking of the tip by insoluble products, such as zinc salts or oxides. The amperometric curves were obtained alternately under anodic and cathodic polarization of the tip. The cathodic 
polarization of the tip will cause a local $\mathrm{pH}$ rise within the diffusion layer that may produce precipitation of zinc oxides at the tip, thus decreasing the current in subsequent scans. Ultimately, a local $\mathrm{pH}$ rise could also promote the precipitation of corrosion products at the substrate, along the line scanned by the UME; still, these products probably re-dissolve due to a decrease in the $\mathrm{pH}$ as the probe moves away from the surface.

\section{3. $p H=5$}

The main electrochemical reactions at this $\mathrm{pH}$ are zinc oxidation, oxygen reduction - Eq. (3), and water reduction - Eq. (4) [59]. The amperometric line scans (Figure 7) show positive feedback for the oxidation current, in the shape of two broad peaks separated by approximately $400 \mu \mathrm{m}$. The width and intensity of these peaks varied with time, but still their separation was always below the total width of the cut edge sample (full width at half maximum $=700 \mu \mathrm{m}$ ).

The spontaneous potential was nearly constant even for long times and of approximately -1.05 $\mathrm{V}$; at this potential, iron is immune while zinc is active. The dissolved zinc cations migrate towards the cathode and precipitate in rings near the steel/zinc interface [66,67] where the $\mathrm{pH}$ goes up by several units [59] due to the reduction of oxygen. This precipitation occurs at ca. $200 \mu \mathrm{m}$ from the steel-zinc interfaces - Figure 8. This means that at these sites the $\mathrm{pH}$ is significantly higher than on the remaining surface of the steel. Further, at $\mathrm{pH}$ above $\sim$, the stable form of zinc will be $\mathrm{ZnO}$, carbonates, hydroxychloride, or possibly simonkolleite [63], i.e. zinc will be in a state of pseudo-passivity and therefore oxidation occurs in a relatively localized manner.

The ionic current line scans obtained with the SVET are quite different from the SECM feedback currents. The SVET probe is placed at a distance from the surface that is roughly ten times bigger than the height of the SECM probe, making the results more averaged. The arbitrary line scans measured across the sample and depicted in Figure 9 distinguish clearly two narrow anodes and one central cathode. The cathodic plateau is approximately $\sim 500 \mu \mathrm{m}$ wide and corresponds to the steel, while the narrow anodes correspond to zinc. After the first hour, the zinc anode on the right side becomes inactive and only the other zinc edge, corresponding to the side with the organic coating remained anodic.

\section{Discussion}

One major issue of this work is the $\mathrm{pH}$ at the surface of the cut edge. The solutions used were not buffered and so it is known that the $\mathrm{pH}$ on the surface will change within the diffusion layer of the cut edge as a consequence of the reactions at the substrate. Several studies have shown that the pH on 
the steel surface can increase by several units, from natural $\mathrm{pH}(\sim 5)$ to 10, as shown by Ogle et al. [54]. At pH5 zinc would be active presenting uniform dissolution, whereas at the center of the steel, the passivity predicted by the Pourbaix diagrams for $\mathrm{pH}>8$ results in the formation of a thin layer of $\mathrm{ZnO}$ that re-dissolves locally below $\mathrm{pH} 10$. This explains why in the neutral solution the dissolution of zinc occurs in a localized manner, with the anodes shifting along the surface. At the spontaneous potential of the galvanic couple, steel is immune and the oxides formed in the atmosphere previously to the immersion will be reduced, providing a clean conductive surface effective in the regeneration of the mediator.

In the alkaline solution the local $\mathrm{pH}$ is not expected to increase significantly when compared to the bulk value. The corrosion kinetics should be slow, with zinc dissolution taking place very much like in the neutral solution, i.e., in a localized manner, while steel is immune. The feedback current is very low and decreases rapidly, which means that the surface gets covered by corrosion products quite fast and measurements could only be performed for relatively short exposures.

In acidic solution the initial bulk $\mathrm{pH}$ is 2 but quickly increases in the vicinity of the surface. The actual $\mathrm{pH}$ at the surface was not measured but at the free corroding potential of the sample, steel is expected to be immune for a wide range of $\mathrm{pH}$, whereas zinc is active up to neutral $\mathrm{pH}$. Therefore, reduction of $\mathrm{H}^{+}$and of $\mathrm{H}_{2} \mathrm{O}$ will take place on steel and will contribute to alkalinization near the surface. Once the electrolyte becomes less acidic, the predominating reaction on steel shall be the reduction of $\mathrm{O}_{2}$. The evolution of molecular hydrogen was visible at the sides of the sample, on zinc, during the whole duration of the experiment, meaning that the reduction of water proceeds on the zinc layer, or at least in its close proximity. The equilibrium potential for water reduction is $-0.79 \mathrm{~V}$ at $\mathrm{pH} 10,-0.49 \mathrm{~V}$ at $\mathrm{pH} 5$, and $-0.32 \mathrm{~V}$ vs. $\mathrm{Ag} / \mathrm{AgCl}, 3 \mathrm{M} \mathrm{KCl}$ at $\mathrm{pH} 2$ [63]. The discharge current, however, only becomes significant at potentials more negative than the equilibrium value. Therefore, in principle, proton reduction could only be sensed by the probe biased at $-0.50 \mathrm{~V}$ at either $\mathrm{pH} 10$ or $\mathrm{pH}$ 5. The voltammetric plot at $\mathrm{pH} 2$ shows a plateau at potentials ranging from -0.30 to $-0.60 \mathrm{~V}$, assigned to the reduction of dissolved oxygen. Further, near the surface of the cut edge the $\mathrm{pH}$ will rise to a nearly neutral value. Zinc is anodic, which means that the rate of the cathodic reaction on its surface is quite small compared to the one occurring at the steel. The high rate of the anodic reaction causes fast dissolution of zinc, with loss of galvanic action. After that, the free corroding potential of the cut edge becomes more positive and the $\mathrm{pH}$ is likely to decrease to the initial bulk value, as the production of $\mathrm{OH}^{-}$ions occurs at a lower rate. Therefore we conclude that our measurements with the probe biased at $-0.50 \mathrm{~V}$ correspond to oxygen depletion at the cut edge surface. After zinc dissolution, corrosion of steel may then start, but part of the surface will be covered with corrosion products formed during the previous step while zinc was active, therefore losing its surface conductivity. Further, the 
maximum in the feedback current cannot be explained by topography. Though an alternative cause for this maximum might be the oxidation at the tip of molecular hydrogen formed at the cathodic sites on the surface, this was discarded because the evolution of hydrogen occurred at both edges of the sample, whereas the feedback current only exhibited a maximum on one of the edges. This local maximum may alternatively be due to the oxidation of $\mathrm{Fe}^{2+}$ ions to $\mathrm{Fe}^{3+}$, on an active steel surface after the dissolution of the zinc layer $[30,68]$.

In the $\mathrm{pH} 5$ experiment, the two maxima on the sides are clearly located above the steel, at some distance from the edge. At this $\mathrm{pH}$ only the zinc is dissolving and corrosion products precipitate in specific regions, between the zinc where the $\mathrm{pH}$ is acidic and the steel center where the $\mathrm{pH}$ becomes more alkaline. These maxima could in principle arise from topographic effects and consequently would be related with the accumulation of corrosion products on the surface. However, the zinc oxides cannot be more conductive than the steel surface. The accumulation of zinc oxides on steel has been reported to leave clean areas near the surface where the precipitation does not occur $[51,68]$. This actually matches quite well the pattern of ferrocenemethanol feedback current: the accumulation of corrosion products takes place on the sides of the sample near the zinc and at the centre, where zinc precipitation is less significant, the surface remains more conductive. Therefore we conclude that the maximum in the feedback current is located close, but not above the corrosion products, corresponding indeed to electroactive regions close to the steel center.

In order to compare the sensitivity of SVET and the SECM for the zinc, profiles obtained with both techniques after $\sim 15$ min exposure in pH 5 are presented in Figure 10. The plots evidence good agreement and complementarities between the two techniques, as the distribution of ionic currents in solution measured with the SVET matches the locations for regeneration of the redox mediator employed in SECM. Ionic currents arising from the cathodic reaction distributed rather uniformly above the steel center in the region limited by the corrosion products. The location for positive feedback currents in SECM was also above the steel, and the highest values were located in the proximity of the interfaces between the corrosion products and the steel surface, where the density of current lines and the $\mathrm{pH}$ gradients should be higher. The step size employed in these measurements was $10 \mu \mathrm{m}$ for both techniques and it is clear that, despite the probe size being in the same order of magnitude as the zinc layer thickness, the location of the anodes was unambiguously established using the SVET. The disappearance of one anode can be explained by the localized character of zinc corrosion.

The SVET is recognized as a highly sensitive technique for the detection of local anodes and cathodes at the surface of a corroding substrate. In our results the lateral anodes and the central cathode are clearly identified and the width of the cathode (estimated from the distance between the two zero 
current points) is $\sim 605 \mu \mathrm{m}$, which corresponds to $75 \%$ of the actual steel thickness. The position of the microprobe, located $100 \mu \mathrm{m}$ above the surface, together with the larger size of the probe (20 $\mu \mathrm{m})$ results in some attenuation of the signal. Comparatively, the SECM uses a smaller probe and the distance to the substrate was only $\sim 20 \mu \mathrm{m}$. Attenuation is therefore smaller and the fluctuations on surface reactivity more significant. The size of the UME is similar to that of the zinc electrodes and therefore the information on the zinc cannot be resolved. Further, the zinc layers are about ten times smaller than the steel they are coating. The feedback current measured at the sides of the cut edge will be masked by the higher currents measured close to its center and so the measured currents correspond to the steel (almost) exclusively. This is a difference when studying a cut edge configuration or a galvanic couple where the metals are physically separated. In the cut edge, the diffusion of dissolved species complicates the interpretation of data while in the later, the respective reactions occurring at dissimilar materials can be followed in a straightforward fashion allowing physical models to be elaborated. The galvanic couple assembly might provide complementary information regarding the resolution of the SECM for the small zinc electrode and sensitivity towards precipitated corrosion products and will be the object of a future study.

\section{Conclusions}

Imaging of cut edge corrosion was performed using SECM and SVET and provided information on the conductivity and on the evolution of the cathodic reactions on the surface of a cut edge. The SVET provided information on the anodic activity on the thin zinc electrodes, whereas the feedback current for the oxidation of $\mathrm{FcMeOH}$, used as mediator, provided information mostly on the steel surface. The feedback currents measured with the SECM gave decreasing values with time, which may be due to blocking of the tip.

A maximum of the feedback observed over the cut edge is consentaneous with the existence of a conductive surface on steel and with the thermodynamic stability of iron cations in the reduced form. Further, in acidic solution depletion of oxygen at the surface perfectly overlapped the region with highest conductivity at the cut edge.

Non-uniform conductivity of the steel surface was observed at $\mathrm{pH} 5$, which suggests an effect of the accumulation of zinc corrosion products at the cathodic regions of the material. The feedback current correlated well with the ionic current flows in solution.

The interpretation of the processes in each environment takes into account the variations of the $\mathrm{pH}$ due to local electrochemical reactions. Within the experimental conditions, some open questions remain concerning the feedback response coming from the thin zinc anodes. 


\section{Acknowledgments}

A. Marques acknowledges the Portuguese Foundation for Science and Technology (FCT) for PhD grant SFRH/BD/72161/2010. J. Izquierdo and R.M. Souto are grateful for financial support by the MINECO (Madrid, Spain) and the European Regional Development Fund (Brussels, Belgium) under Project No. CTQ2012-36787, and a Research Training Grant awarded to J.I. by the Spanish Ministry of Education (MECD, Madrid, Programa de Formación de Personal Investigador).

\section{References}

1. P. Marcus, F. Mansfeld (Eds.), Analytical Methods in Corrosion Science and Engineering, CRC Press, Boca Raton, FL (2006).

2. H.S. Isaacs, G. Kissel, Surface preparation and pit propagation in stainless steels, J. Electrochem. Soc., 119 (1972) 1628-1632.

3. R. Akid, D.J. Mills, A comparison between conventional macroscopic and novel microscopic scanning electrochemical methods to evaluate galvanic corrosion, Corros. Sci., 43 (2001) 12031216.

4. N. Cui, H.Y. Ma, J.L. Luo, S. Chiovelli, Use of scanning reference electrode technique for characterizing pitting and general corrosion of carbon steel in neutral media, Electrochem. Commun., 3 (2001) 716-721.

5. B. Lin, R. Hu, C. Ye, Y. Li, C. Lin, A study on the initiation of pitting corrosion in carbon steel in chloride-containing media using scanning electrochemical probes, Electrochim. Acta, 55 (2010) $6542-6545$.

6. Y. Zou, J. Wang, Q. Bai, L.L. Zhang, X. Peng, X.F. Kong, Potential distribution characteristics of mild steel in seawater, Corros. Sci., 57 (2012) 202-208.

7. G. Williams, H.N. McMurray, D. A. Worsley, Cerium(III) inhibition of corrosion-driven organic coating delamination studied using a scanning Kelvin probe technique, J. Electrochem. Soc., 149 (2002) B154-B162.

8. G. Klimow, N. Fink, G. Grundmeier, Electrochemical studies of the inhibition of the cathodic delamination of organically coated galvanised steel by thin conversion films, Electrochim. Acta, 53 (2007) 1290-1299.

9. J.M. Sykes, M. Doherty, Interpretation of Scanning Kelvin Probe potential maps for coated steel using semi-quantitative current density maps, Corros. Sci., 50 (2008) 2773-2778. 
10. R. Hausbrand, M. Stratmann, M. Rohwerder, The physical meaning of electrode potentials at metal surfaces and polymer/metal interfaces: Consequences for delamination, J. Electrochem. Soc., 155 (2008) C369-C379.

11. T. Pan, Corrosion behavior of a duplex stainless steel under cyclic loading: a scanning Kelvin probe force microscopy (SKPFM) based microscopic study, J. Appl. Electrochem., 42 (2012) 1049-1056.

12. H.S. Isaacs, M.W. Kendig, Determination of surface inhomogeneities using a scanning probe impedance technique, Corrosion, 36 (1980) 269-274.

13. R.S. Lillard, P.J. Moran, H.S. Isaacs, A novel method for generating quantitative local electrochemical impedance spectroscopy, J. Electrochem. Soc., 139 (1992) 1007-1012.

14. S.R. Taylor, Incentives for using local electrochemical impedance methods in the investigation of organic coatings, Prog. Org. Coat., 43 (2001) 141-148.

15. J.-B. Jorcin, E. Aragon, C. Merlatti, N. Pébère, Delaminated areas beneath organic coating: A local electrochemical impedance approach, Corros. Sci., 48 (2006) 1779-1790.

16. C.F. Dong, X. Tang, Y.F. Cheng, Corrosion of steel under the defected coating studied by localized electrochemical impedance spectroscopy, Electrochim. Acta, 53 (2008) 4740-4747.

17. A. Rubin, R. Oltra, B. Vuillemin, K. Ogle, Impedance characterization of the electrochemical environment under a polymer film artificially delaminated, Electrochim. Acta, 53 (2008) 64846488.

18. H.S. Isaacs, Y. Ishikawa, Applications of the vibrating probe to localized current measurements, in: R. Baboian (Ed.), Electrochemical Techniques for Corrosion Engineering, NACE, Houston, TX (1986), pp. 17-23.

19. H.S. Isaacs, The localized breakdown and repair of passive surfaces during pitting, Corros. Sci., 29 (1989) 313-323.

20. D. Worsley, H.N. McMurray, A. Belghazi, Determination of localised corrosion mechanisms using a scanning vibrating reference electrode technique, Chem. Commun., (1997) 2369-2370.

21. H.S. Isaacs, The measurement of the galvanic corrosion of soldered copper using the scanning vibrating electrode technique, Corros. Sci., 28 (1988) 547-588.

22. M.J. Franklin, D.C. White, H.S. Isaacs, Pitting Corrosion by bacteria on carbon steel, determined by the scanning vibrating electrode technique, Corros. Sci., 9 (1991) 945-952.

23. A.J. Bard, F.R. Fan, M.V. Mirkin, Scanning electrochemical microscopy, in: A.J. Bard (Ed.), Electroanalytical Chemistry, vol. 18, Marcel Dekker, New York (1994) pp. 243-373. 
24. D.O. Wipf, A.J. Bard, Scanning electrochemical microscopy. VII. Effect of heterogeneous electron-transfer rate at the substrate on the tip feedback current, J. Electrochem. Soc., 138 (1991) 469-474.

25. D.O. Wipf, A.J. Bard, Scanning electrochemical microscopy. X. High resolution imaging of active sites on an electrode surface, J. Electrochem. Soc., 138 (1991) L4-L6.

26. S.E. Pust, W. Maier, G. Wittstock, Investigation of localized catalytic and electrocatalytic processes and corrosion reactions with scanning electrochemical microscopy (SECM), Z. Phys. Chem., 222 (2008) 1463-1517.

27. L. Niu, Y. Yin, W. Guo, M. Lu, R. Qin, S. Chen, Application of scanning electrochemical microscope in the study of corrosion of metals, J. Mat. Sci., 44 (2009) 4511-4521.

28. C.H. Paik, H.S. White, R.C. Alkire, Scanning electrochemical microscopy detection of dissolved sulfur species from inclusions in stainless steel, J. Electrochem. Soc., 147 (2000) 4120-4124.

29. K. Fushimi, M. Seo, An SECM observation of dissolution distribution of ferrous or ferric ion from a polycrystalline iron electrode, Electrochim. Acta, 47 (2001) 121-127.

30. A.C. Bastos, A.M. Simões, S. González, Y. González-García, R.M. Souto, Imaging concentration profiles of redox-active species in open-circuit corrosion processes with the scanning electrochemical microscope, Electrochem. Commun., 6 (2004) 1212-1215.

31. R.M. Souto, Y. González-García, D. Battistel, S. Daniele, On the use of mercury-coated tips in scanning electrochemical microscopy to investigate galvanic corrosion processes involving zinc and iron, Corros. Sci., 55 (2012) 401-406.

32. Y.Y. Zhu, D.F. Williams, Scanning Electrochemical microscopic observation of a precursor state to pitting corrosion of stainless steel, J. Electrochem. Soc., 144 (1997) L43-L45.

33. H. Tanabe, K. Togashi, T. Misawa, U. Kamachi Mudali, In-situ observation of dynamic reacting species at pit precursors of nitrogen-bearing austenitic stainless steels, J. Mat. Sci. Lett., 17 (1998) 551-553.

34. L.F. Garfias-Mesias, M. Alodan, P.I. James, W.H. Smyrl, Determination of precursor sites for pitting corrosion of polycrystalline titanium by using different techniques, J. Electrochem. Soc., 145 (1998) L64-L66.

35. M.A. Malik, P.J. Kulesza, Monitoring of conductivity changes in passive layers by scanning electrochemical microscopy in feedback mode: Localization of pitting precursor sites on surfaces of multimetallic phase materials, Anal. Chem., 79 (2007) 3996-4005.

36. D.O. Wipf, Initiation and study of localized corrosion by scanning electrochemical microscopy, Colloids Surf. A, 93 (1994) 251-261. 
37. Y. González-García, G.T. Burstein, S. González, R.M. Souto, Imaging metastable pits on austenitic stainless steel in situ at the open-circuit corrosion potential, Electrochem. Commun., 6 (2004) 637642.

38. C. Gabrielli, S. Joiret, M. Keddam, N. Portail, P. Rousseau, V. Vivier, Single pit on iron generated by SECM. An electrochemical impedance spectroscopy investigation, Electrochim. Acta 53 (2008) 7539-7548.

39. R.M. Souto, Y. González-García, S. González, G.T. Burstein, Damage to paint coatings caused by electrolyte immersion as observed in situ by scanning electrochemical microscopy, Corros. Sci., 46 (2004) 2621-2628.

40. A.M. Simoes, D. Battocchi, D.E. Tallman, G.P. Bierwagen, SVET and SECM imaging of cathodic protection of aluminium by a Mg-rich coating, Corros. Sci., 49 (2007) 3838-3849.

41. R.M. Souto, Y. González-García, S. González, G.T. Burstein, Imaging the origins of coating degradation and blistering caused by electrolyte immersion assisted by SECM, Electroanalysis, 21 (2009) 2569-2574.

42. D.A. Walsh, L.E. Li, M.S. Bakare, K.T. Voisey, Visualisation of the local electrochemical activity of thermal sprayed anti-corrosion coatings using scanning electrochemical microscopy, Electrochim. Acta, 54 (2009) 4647-4654.

43. R.M. Souto, Y. González-García, S. González, In situ monitoring of electroactive species by using the scanning electrochemical microscope. Application to the investigation of degradation processes at defective coated metals, Corros. Sci., 47 (2005) 3312-3323.

44. R.M. Souto, L. Fernández-Mérida, S. González, SECM imaging of interfacial processes in defective organic coatings applied on metallic substrates using oxygen as redox mediator, Electroanalysis, 21 (2009) 2640-2646.

45. R.M. Souto, Y. González-García, J. Izquierdo, S. González, Examination of organic coatings on metallic substrates by scanning electrochemical microscopy in feedback mode: revealing the early stages of coating breakdown in corrosive environments, Corros. Sci., 52 (2010) 748-753.

46. J.J. Santana, J. González-Guzmán, L. Fernández-Mérida, S. González, R.M. Souto, Visualization of local degradation processes in coated metals by means of scanning electrochemical microscopy in the redox competition mode, Electrochim. Acta, 55 (2010) 4488-449.

47. Y. Gonzalez-Garcia, J.M.C. Mol, T. Muselle, I. De Graeve, G. Van Assche, G. Scheltjens, B. Van Mele, H. Terryn, SECM study of defect repair in self-healing polymer coatings on metals, Electrochem. Commun., 13 (2011) 169-173.

48. A. Pilbáth, T. Szabó, J. Telegdi, L. Nyikos, SECM study of steel corrosion under scratched microencapsulated epoxy resin, Prog. Org. Coat., 75 (2012) 480-485. 
49. F. Zou, C. Barreau, R. Hellouin, D. Quantin, D. Thierry, Application of scanning vibrating electrode techniques to study the degradation of coil-coated steel at edges, Mater. Sci. Forum, 289292 (1998) 83-92.

50. S. Bohm, H.N. McMurray, S.M. Powell, D. Worsley, Photoelectrochemical investigation of corrosion using scanning electrochemical techniques, Electrochim. Acta, 45 (2000) 2165-2174.

51. K. Ogle, V. Baudu, L. Garrigues, X. Philippe, Localized electrochemical methods applied to cut edge corrosion, J. Electrochem. Soc., 147 (2000) 3654-3660.

52. D.A. Worsley, D. Williams, J.S.G. Ling, Mechanistic changes in cut edge corrosion induced by variation of organic coating porosity, Corros. Sci., 43 (2001) 2335-2348.

53. A.C. Bastos, A.M. Simões, M.G. Ferreira, Corrosion of electrogalvanized steel in $0.1 \mathrm{M} \mathrm{NaCl}$ studied by SVET, Port. Electrochim. Acta, 21 (2003) 371-387.

54. K. Ogle, S. Morel, D. Jacquet, Observation of self-healing functions on the cut edge of galvanized steel using SVET and pH microscopy, J. Electrochem. Soc., 153 (2006) B1-B5.

55. A. Alvarez-Pampliega, S.V. Lamaka, M.G. Taryba, M. Madari, J. De Strycker, E. Tourwé, M.G.S. Ferreira, H. Terryn, Cut edge corrosion study on painted aluminum rich metallic coated steel by scanning vibrating electrode and micro-potentiometric techniques, Electrochim. Acta, 61 (2012) 107-117.

56. E. Tada, K. Sugawara, H. Kaneko, Distribution of $\mathrm{pH}$ during galvanic corrosion of a Zn/steel couple, Electrochim. Acta, 49 (2004) 1019-1026.

57. A.P. Yadav, H. Katayama, K. Noda, H. Masuda, A. Nishikata, T. Tsuru, Surface potential distribution over a zinc/steel galvanic couple corroding under thin layer of electrolyte, Electrochim. Acta, 52 (2007) 3121-3129.

58. T.A. Lowe, G.G. Wallace, A.K. Neufeld, Insights into the cut edge corrosion of 55\% Al-Zn metal coating on steel from simultaneous electrochemical polarization and localised $\mathrm{pH}$ sensing experiments, Corros. Sci., 55 (2012) 180-186.

59. F. Thébault, B. Vuillemin, R. Oltra, K. Ogle, C. Allely, Investigation of self-healing mechanism on galvanized steels cut edges by coupling SVET and numerical modeling, Electrochim. Acta, 53 (2008) 5226-5234.

60. A.M. Simões, A.C. Bastos, M.G. Ferreira, Y. González-García, S. González, R.M. Souto, Use of SVET and SECM to study the galvanic corrosion of an iron-zinc cell, Corros. Sci., 49 (2007) 726739.

61. B.M. Fernández-Pérez, J. Izquierdo, S. González, R.M. Souto, Scanning electrochemical microscopy studies for the characterization of localized corrosion reactions at cut edges of coilcoated steel, J. Solid State Electrochem., 18 (2014) 2983-2992. 
62. S. Thomas, N. Birbilis, M.S. Venkatraman, I.S. Cole, Corrosion of zinc as a function of $\mathrm{pH}$, Corrosion 68 (2013) 015009-1-9.

63. M. Pourbaix, Atlas of Electrochemical Equilibra in Aqueous Solutions. National Association of Corrosion Engineers, Houston, Texas (1974).

64. J. Zhou, Y. Zu, A.J. Bard, Scanning electrochemical microscopy. Part 39. The proton/hydrogen mediator system and its application to the study of the electrocatalysis of hydrogen oxidation, J. Electroanal. Chem., 491 (2000) 22-29.

65. K. Fushimi, K.A. Lill, H. Habazaki, Heterogeneous hydrogen evolution on corroding Fe-3at.\% Si surface observed by scanning electrochemical microscopy, Electrochim. Acta, 52 (2007) 42464253.

66. A.M. Simões, J.C.S. Fernandes, Studying phosphate corrosion inhibition at the cut edge of coil coated galvanized steel using the SVET and EIS, Prog. Org. Coat., 69 (2010) 219-224.

67. J. Izquierdo, L. Nagy, S. González, J.J. Santana, G. Nagy, R.M. Souto, Resolution of the apparent experimental discrepancies observed between SVET and SECM for the characterization of galvanic corrosion reactions, Electrochem. Commun., 27 (2013) 50-53.

68. A.M. Simões, J. Torres, R. Picciochi, J.C.S. Fernandes, Corrosion inhibition at galvanized steel cut edges by phosphate pigments, Electrochim. Acta, 54 (2009) 3857-3865
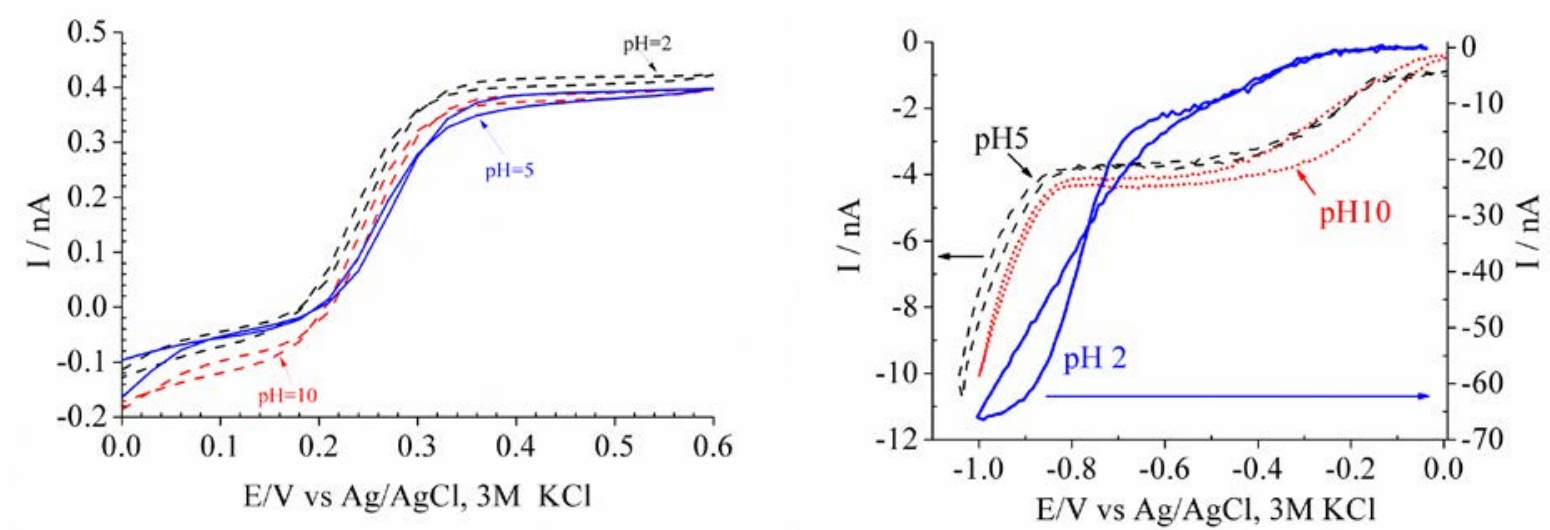

Figure 1. Cyclic voltammograms measured at the SECM tip in the bulk electrolyte for (a) the oxidation of FcMeOH under diffusion limiting conditions; and (b) cathodic potentials immediately after immersion. Scan rate: $20 \mathrm{mV} \mathrm{s}^{-1}$. 


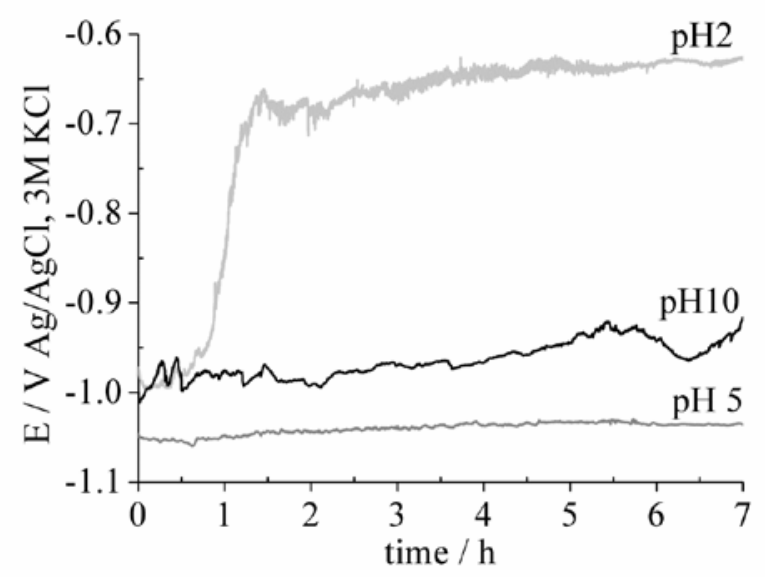

Figure 2. Open-circuit potential measurements; the respective electrolyte $\mathrm{pH}$ is indicated next to each trace.

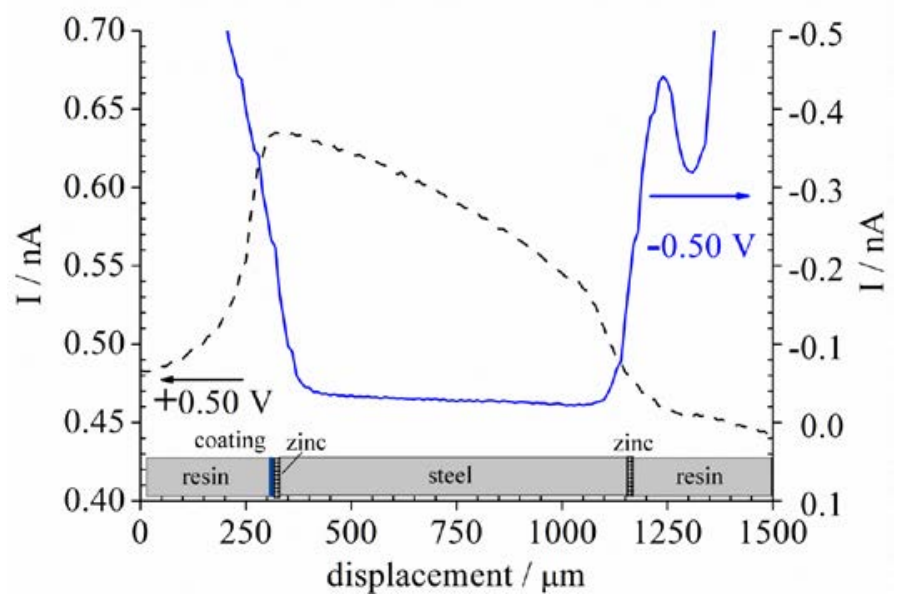

Figure 3. SECM line scans measured as the tip travelled over the cut edge exposed to test solution of $\mathrm{pH}=2$ for 30 min exposure durations. Tip potential is indicated in the graph; scan rate: $5.60 \mu \mathrm{m} \mathrm{s}^{-1}$ 


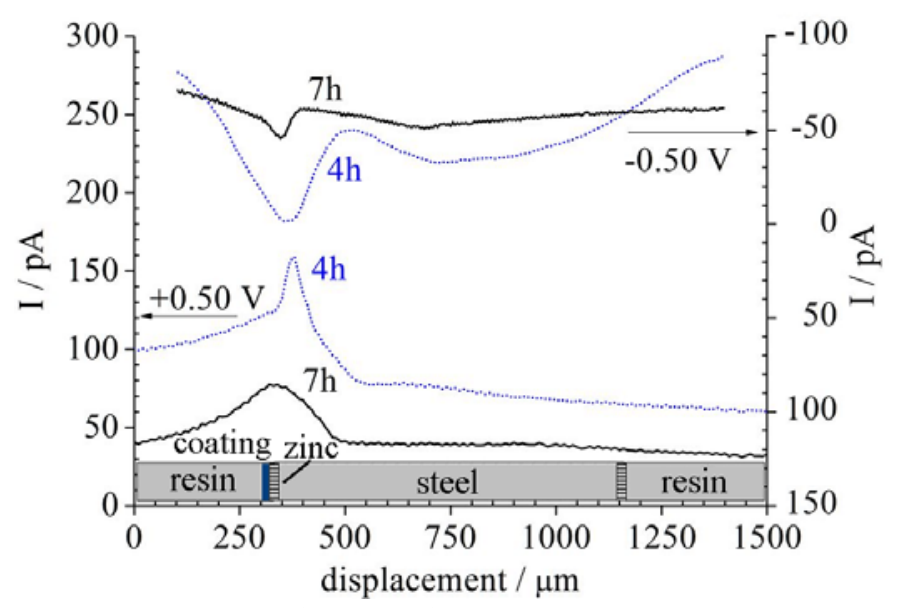

Figure 4. SECM line scans measured as the tip travelled over the cut edge exposed to test solution of $\mathrm{pH}=2$. Tip potential values and exposure times are indicated in the graph. Scan rate: $5.60 \mu \mathrm{m} \mathrm{s}^{-1}$.

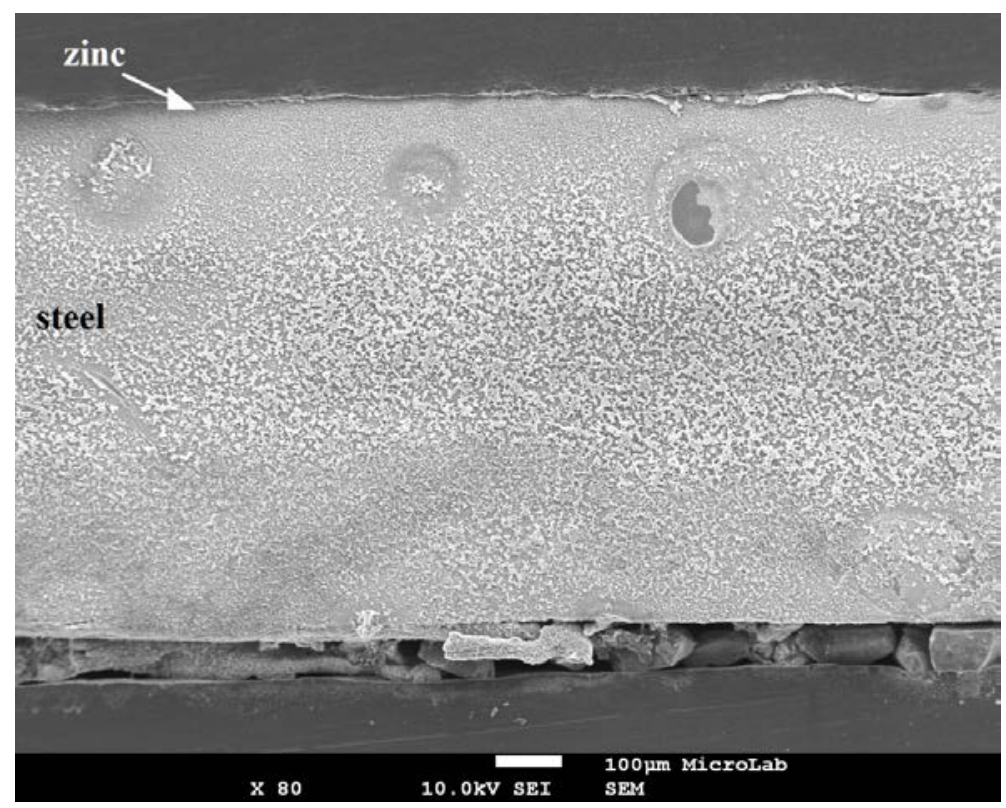

Figure 5. SEM micrographs of the cut edge retrieved from the test solution of $\mathrm{pH}=2$ after $7 \mathrm{~h}$ exposure time. The side coated with the organic coating is located at the bottom. 


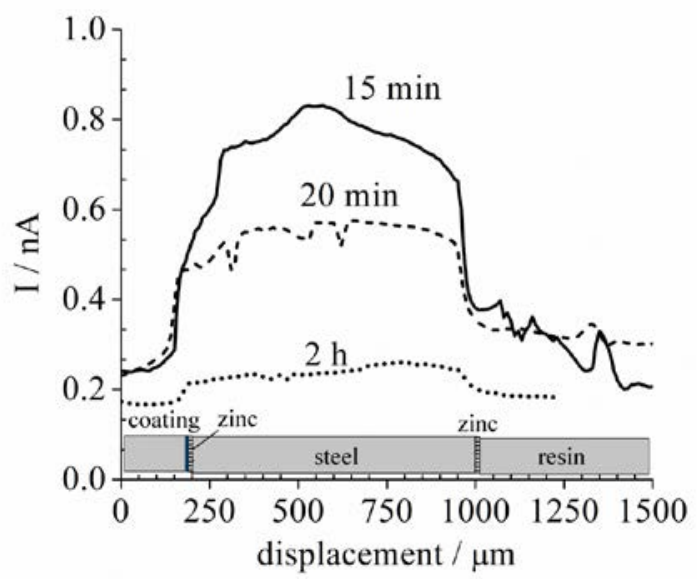

Figure 6. SECM line scans measured as the tip travelled over the cut edge exposed to test solution of $\mathrm{pH}=10$ for various exposure durations indicated in the graph. Tip potential: $+0.45 \mathrm{~V}$; scan rate: $5.60 \mu \mathrm{m} \mathrm{s}^{-1}$. 


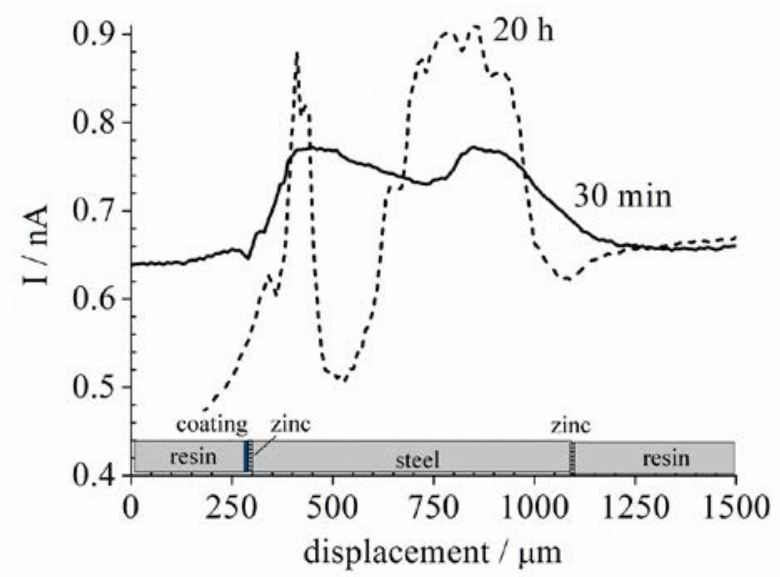

Figure 7. SECM line scans measured as the tip travelled over the cut edge exposed to test solution of $\mathrm{pH}=5$ for various exposure durations indicated in the graph. Tip potential: $+0.45 \mathrm{~V}$; scan rate: $5.60 \mu \mathrm{m} \mathrm{s}{ }^{-1}$.

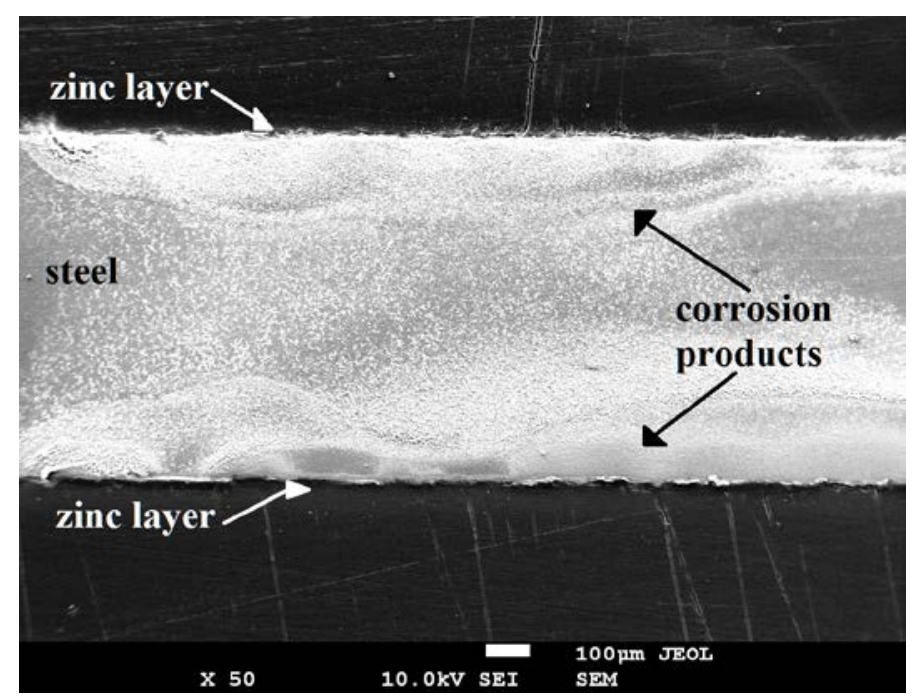

Figure 8. SEM micrograph of the cut edge exposed to test solution of $\mathrm{pH}=5$ taken at the end of the experiment. 


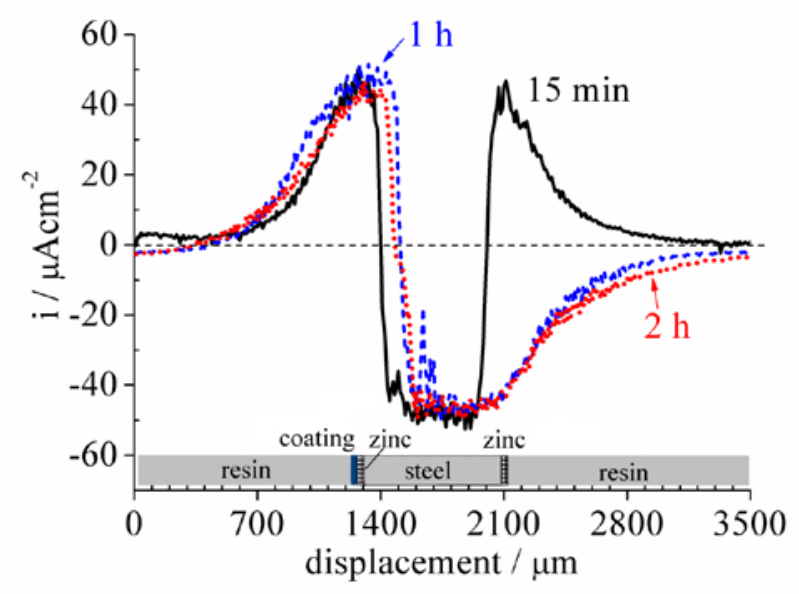

Figure 9. Line scans measured by SVET over the cut edge exposed to test solution of $\mathrm{pH}=5$ for various exposure durations indicated in the graph.

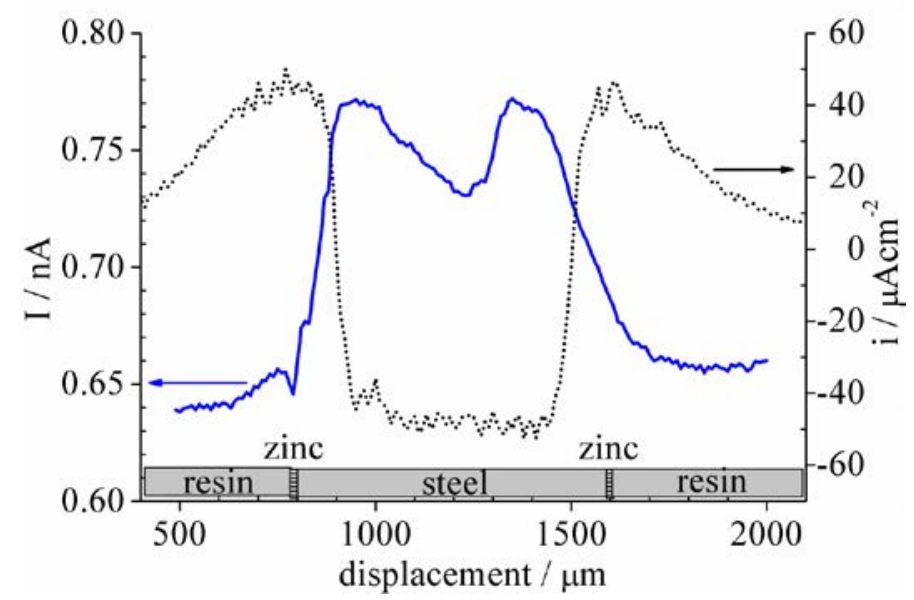

Figure 10. Line scans taken from Figures 7 and 9, corresponding to SECM and SVET measurements of the cut edge exposed to test solution of $\mathrm{pH}=5$ for $30 \mathrm{~min}$. 